\title{
SINDROME DE INMUNODEFICIENCIA ADQUIRIDA
}

\author{
IVAN YUNIS M. *
}

\section{INTRODUCCION}

El síndrome de inmunodeficiencia adquirida (SIDA), una nueva epidemia circunscrita en gran parte a los homosexuales masculinos de algunas ciudades de los Estados Unidos de América, intriga a la comunidad científica, sembrando el pánico en el público. Alrededor de dos mil casos notificados y una tasa de mortalidad que amenaza con ser superior al $90 \%$ y el hecho de que nada se ha podido hacer por detener la epidemia han logrado que el Servicio de Salud de los Estados Unidos considere este problema como "prioridad número 1".

A pesar de todo lo que se ha escrito al respecto, hay muy pocas cosas claras sobre la naturaleza del síndrome. Presentamos aquí una revisión de sus aspectos más sobresalientes.

\section{EPIDEMIOLOGIA}

Cronología. En Julio de 1981, una nota epidemiológica de los Centers for Disease Control (CDC) (1) de Atlánta, reveló que en los últimos treinta meses se habían informado en los Estados Unidos 26 casos de sarcoma de Kaposi (SK), todos en hombres homosexuales, de edades comprendidas entre los 26 y los 51 años (edad promedio de 39 años), de los cuales 20 eran de la ciudad de New York y 6 del estado de California. Cuatro de estos pacientes presentaban además neumonía por Pneumocystis carinii (NPG), hallazgo que inmediatamente se relacionaba con otros registros del CDC (2) según los cuales, desde septiembre de 1979 se habían venido presentando casos de NPC entre hombres homosexuales en California.

En agosto de 1980 se diagnosticó SK y NPC en haitianos inmigrantes residentes en los Estados Unidos, y poco después se supo de 11 casos más en Haití (3). Los haitianos no eran drogadictos ni homosexuales.

Un año después, el CDC declara haber recibido informes de 107 casos de SK y/o NPC (4). En esa época, dicho organismo comenzó a encontrar rastros de transmisión directa de la enfermedad, identificando los nombres de varias víctimas y asociándolos con la aparición de nuevos casos (5).

Hacia diciembre de 1981 el número de casos había ascendido a 180 y se incrementaba en unos 7-10 semanales. Aparecen entonces los primeros casos en Europa, contando entre ellos 6 daneses $(6,9) \quad 2$ franceses (7), 2 españoles (8), un inglés y un colombiano residente en los Estados Unidos $(8,10)$.

En el verano de 1982, el CDC anota por primera vez la aparición de SIDA en hemofílicos (11) y un poco después, en 7 pacientes quirúrgicos con transfusiones sanguíneas recientes. En el otoño de 1982, la enfermedad ya había afectado a otros grupos como drogadictos, y mujeres cuyos compañeros sexuales eran drogadictos o bisexuales, enfermos o no con SIDA (12).

En enero de 1982 el CDC publica la noticia de 26 niños con síntomas de SIDA, varios de los cuales han fallecido ya (13). El número de

Estudiante de Medicina, Universidad del Rosario. En rotación Unidad de Inmunología, Grupo de Microbiología e Inmunología. Instituto Nacional de Salud. Bogotá. 
casos se ha venido duplicando cada seis meses, y hoy, se registran más de 20 nuevos casos por semana; no obstante la rapidez con que ha avanzado la epidemia, el número diario de nuevos casos en los últimos meses no ha mostrado el incremento esperado.

La tasa de mortalidad para los casos registrados es del $38 \%$, pero se estima que la tasa futura a los 5 años será del 90-95\% (14), ya que ningún caso ha revertido hasta el momento.

Rasgos epidemiológicos. Los grupos más afectados son en su orden: hombres homosexuales o bisexuales (71\%); drogadictos heterosexuales $(17 \%)$; haitianos inmigrantes en los EUA (5\%); otros: como los receptores de transfusiones sanguíneas, los hijos de enfermos de SIDA, los contactos heterosexuales de casos de SIDA, y los presos $(6 \%)$; hemofílicos (1\%) (15).

Alrededor del 90\% de los casos se presentan entre los 20 y los 49 años, y el $60 \%$ de los casos en sujetos de raza blanca. La gran mayoría de los casos se concentran en los estados de New York (44\%), California $(16 \%)$, y el resto en otros estados. Algunos de los rasgos más sobresalientes respecto de los individuos afectados son: en el caso de los homosexuales, el dato más sobresaliente es el de que los enfermos tienen un índice de promiscuidad bastante alto, con un promedio de contactos sexuales con 1100 diferentes personas durante la vida, contra 500 en el grupo control de homosexuales no enfermos (16).

Parece clara la relación entre el tipo de actividad sexual entre los homosexuales y las características de los linfocitos $\mathrm{T}$; en un estudio, aquellos que practican coito anal como sujetos pasivos en el acto sexual poseen un promedio de linfocitos $T$ supresores más alto que aquellos que actúan como sujetos activos, e incluso en quienes no es frecuente este tipo de actividad sexual (17). Este hallazgo deberá tenerse muy presente en el momento en que entremos a analizar las teorías sobre la etiología del síndrome.

La mayor parte de los casos se encuentran concentrados en ciertas ciudades, caracte- rísticamente populosas, y, al menos en una de ellas, los casos se encuentran en un foco geográfico claramente definido (18).

La gran mayoría de ellos (85\%) afirma haber utilizado drogas del tipo amil-nitritos (19-21) y sólo un pequeño porcentaje $(12,3 \%)$ usa drogas por vía intravenosa.

Ninguno de los individuos afectados acusaba enfermedades crónicas debilitantes ni tratamientos inmunosupresores antes de presentar la sintomatología del síndrome, auncuando es sabido que la comunidad homosexual se ve frecuentemente afectada por infecciones repetidas de sífilis, gonorrea, herpes genital, hepatitis, infecciones por hongos, amebiasis y otros protozoarios.

En un 80-95\% de los casos los títulos de anticuerpos contra Citomegalovirus (CMV) son 13 a 16 veces mayores que en individuos normales (22).

En muchos de los casos se encuentran un antecedente de contacto (sexual generalmente) con otro individuo enfermo, o en quien después aparece la enfermedad. De hecho, en gran parte de los informes de casos se encuentra mencionado el antececente, aunque se considera que la gran mayoría no son el producto de una transmisión directa de un presunto agente etiológico, según los análisis estadísticos hechos por los CDC en el condado de Los Angeles y el análisis del foco epidemiológico de San Francisco (18).

Desde el primer momento, la proporción de casos según su forma de presentación (como SK, NPC, o infecciones por gérmenes oportunistas IGO) se ha mantenido constante (15).

Un dato muy interesante y de particular valor lo constituye el hecho de que no hay casos informados en mujeres homosexuales, aunque hay algunos informes en prostitutas $(23,24)$.

En cuanto se refiere al grupo de los haitianos, algunos de los datos claros con que se cuenta son los siguientes: de los primeros brotes observados en haitianos 
inmigrantes residentes en New York y Miami, en un $88 \%$ eran hombres de edades comprendidas entre los 20 y los 45 años, con un tiempo de residencia en EUA no mayor de tres años; todos negaron ser homosexuales o drogadictos, y de 34 casos iniciales, sólo 2 presentaron SK. El resto presentaba IGO, especialmente NPC. En algunos de los casos de haitianos, se ha comprobado al menos un contacto que apoya la teoría de la transmisión directa de un posible agente etiológico $(25,26)$. Realmente, no se sabe si guarden relación con los brotes semejantes de SIDA vistos en homosexuales y drogadictos, aunque las características inmunológicas son muy similares (27).

Entre los niños, el grupo más afectado es el de los menores de 2 años, en quienes se presentan IGO e inmunodeficiencia celular inexplicable. De los primeros casos informados, varios eran de origen haitiano; todos eran hijos de mujeres drogadictas y presentaban grados variables de desnutrición. La mayor parte tenían hermanos con signos de inmunodeficiencia y la tasa de mortalidad es bastante alta entre ellos (13). Uno de los niños afectados, de 29 meses de edad murió poco después de ser transfundido. El menor, a quien se le hubo de practicar una gran cantidad de transfusiones de sangre completa, desde sus primeros días de vida, murió luego de varias IGO y con diagnóstico de SIDA. Más tarde se comprobó que en una de las transfusiones la sangre provenía de una víctima de SIDA (28).

Los casos registrados en hemofílicos tienen todos un factor común que es el de estar recibiendo tratamiento con concentrados de factor VIII (29) provenientes de grupos de donantes diferentes; en ellos el SIDA aparece principalmente como NPC y otras IGO.

Los casos europeos, alrededor de 100, parecen tener contacto con norteamericanos homosexuales, pero en la revisión de los 29 casos que se han presentado en Francia se afirma que el SIDA puede ser autóctono (30).

Recientemente se han informado casos on africanos de Zaire residentes en Europa, quienes presentan SK o IGO, especialmente criptococosis $(31,32)$. Asimismo, se intenta ahora reevaluar varios casos de infección mortal en años anteriores ocurridas en la franja de Africa Central, con la hipótesis de que podrían ser casos auténticos de SIDA $(30,31,33)$.

Sobre la base de un presunto agente viral como productor del SIDA, se han invocado varias formas de transmisión, como:

- Por coito anal, como enfermedad venérea.

- Por ingestión de semen, en el cual iría contenido el agente.

- Por vía parenteral, como en el caso de las transfusiones de sangre o concentrados de factor VIII, o como en el caso de los drogadictos, quienes comparten jeringas contaminadas.

- Por vía transplacentaria, o en contactos madre-hijo en el período postnatal.

- Por algún medio desconocido, en los bares y casas de baño que frecuentan los homosexuales.

- Durante el coito normal entre una mujer heterosexual y su compañero bisexual.

Siguiendo esta línea de pensamiento, podríamos agregar que las personas con mayor riesgo de contraer la enfermedad en un futuro inmediato serían:

El personal de salud involucrado con pacientes enfermos de SIDA (hospitalario y de laboratorio); hasta el momento no se ha informado el primero;

aquellas mujeres que cohabitan con hombres bisexuales, o cuyos compañeros sexuales son drogadictos;

los niños hijos de los anteriores;

los hemofílicos y, aunque en mucho menor grado;

cualquier persona a quien se le transfunda sangre o cualquiera de sus subproductos, si ésta proviene de un donante enfermo de SIDA (34). 


\section{FISIOPATOLOGIA}

Desde la aparición de la enfermedad no ha sido posible encontrar un agente etiológico que pueda explicar su fisiopatología. Hasta el momento, la teoría más aceptada es la de un agente infeccioso, más específicamente un virus. Si es el mismo CMV responsable de otras infecciones, o una nueva cepa del mismo o aún de otro virus es algo en lo que no hay acuerdo. Para empezar, a pesar de que se ha intentado durante más de tres años, no ha sido posible aislar ninguna partícula viral de los tejidos y secreciones de los enfermos. Dentro de las teorías formuladas hasta el momento tenemos:

que el sistema inmunitario podría llegar a paralizarse por la infección repetida adquirida sexualmente;

que a través de los contactos sexuales anal-oral o anogenital se transmite un virus que destruye la inmunidad, alcanzando la corriente sanguínea a través de soluciones de continuidad de la mucosa rectal.

que el tipo de actividad sexual predominante influye en el desarrollo de la inmunodeficiencia, bien sea por la transmisión de un agente infeccioso o por la transfusión a través de la mucosa rectal de leucocitos alogénicos;

que la sobreexposición al semen tiene un efecto inmunosupresivo capaz de paralizar el sistema inmune;

que las drogas recreacionales del tipo de los nitritos de amilo y butilo podrían "destruír" la inmunidad;

que a través de la vía parenteral se transmita un virus que podría provenir de Africa Central, vía Haití, o incluso autóctono del Caribe, de donde habría pasado a los EUA $(3,16,17,19,21,31,34$, 35).

Como se puede apreciar, la gama de teorías con las que se pretende explicar la enfermedad y su repentina aparición es bastante amplia; no obstante lo complejo que resulta el análisis de los datos, en la actualidad hay algunos de suma importancia que conviene resaltar y que constituyen las pocas cosas claras que se saben de la fisiopatología del síndrome. La infección repetida por CMV en SIDA es un hallazgo constante, así como la producida por el virus del Epstein-Bar (EBV) con títulos de anticuerpos contra EBV 10 a 100 veces más altos de lo normal; también se encuentran elevados los títulos de anticuerpos contra el virus Herpes simple tipo II (HSV). Mientras que la inmunidad humoral parece estar conservada a juzgar por los títulos de inmunoglobulinas normales e incluso elevados vistos en los enfermos, la alteración de la inmunidad celular específica es notoria: existe una franca reducción del número y de la función de la subpoblación de linfocitos $\mathrm{T}$ cooperadores, con una respuesta proliferativa disminuída y una actividad celular baja de los linfocitos conocidos como "asesinos naturales". La función de los neutrófilos es normal (14) pero la de los monocitos está alterada; la relación entre los linfocitos $\mathrm{T}$ cooperadores y los $\mathrm{T}$ supresores (TH/TS) no solo está alterada, sino que en la gran mayoría de los casos se encuentra invertida, hallazgo que contrasta con lo observado en los homosexuales sanos y en otros hombres (36). En un estudio (17) se encontraron diferencias significativas en las relaciones entre los dos grupos de linfocitos T entre los distintos grupos de homosexuales, teniendo en cuenta las siguientes variables: tipo de actividad sexual, número de contactos sexuales por tiempo de vida y número de episodios de enfermedad venérea. Los linfocitos $\mathrm{T}$ cooperadores/inductores, son también conocidos como Leu-3+u OKT4+,y los linfocitos $\mathrm{T}$ citotóxicos/supresores son los mismos Leu- $2+\mathrm{u}$ OKT8 + en los sujetos enfermos, los OKT 4+están particularmente disminuídos, lo cual explica en parte la relación baja entre los TH y los TS (TH/TS), al revés de lo normal: $\mathrm{T} 4+\mathrm{T} 8+=2.0$; (7) los enfermos de SIDA tienen, como ya mencionamos, un número de linfocitos menor que lo normal (generalmente la mitad). Existe producción espontánea del factor inhibidor de la migración de leucocitos, ausencia de producción de interferón leucocitario (IFNalfa) y actividad disminuída de la 5nucleotidasa (6). 
La timosina-alfa, substancia que induce la diferenciación final de las células Tcooperadoras, y que puede estimular a los linfocitos $\mathrm{T}$ a producir linfoquinas, está disminuída, lo cual sugiere una falla de tipo "órgano-terminal" en los enfermos de SIDA (37). De otra parte, varios estudios sugieren que el HLA-DR5 se encuentra en el $65 \%$ de los enfermos de SIDA estudiados, en especial los afectados con SK, contra el $23 \%$ en los individuos de la población general (3).

Los datos epidemiológicos parecen apoyar la teoría según la cual un agente infeccioso sería la causa del SIDA, pero están muy discutidas las formas de infección. De acuerdo con lo que actualmente se sabe, las infecciones virales pueden por sí mismas activar en forma preferencial las células $\mathrm{T}$ supresoras del hombre, reduciendo así la capacidad de respuesta inmune (24). Los linfocitos de pacientes con mononucleosis infecciosa por CMV muestran una baja respuesta a ciertos mitógenos, debido probablemente a un efecto sobre el sistema monocito-macrófago (10). Ahora bien, existen estudios previos que asocian el SK, endémico en Africa Ecuatorial, con infección por CMV (38) y los títulos de seropositividad de CMV en pacientes con SK en los EUA son 13-16 veces más altos que en los individuos normales (22). Otros hallazgos sostienen esta aseveración (12). Lo anterior ha dado pie para pensar que el brote actual de SK puede estar asociado con una reactivación de infecciones latentes de CMV (38). En la enfermedad por CMV, la infección primaria podría constituír luego un estado latente, que sería reactivado, por ejemplo, por un estímulo alogénico. A lo anterior se suman los recientes hallazgos de un aumento de la incidencia, en hombres homosexuales norteamericanos, de enfermedades como el linfoma de Burkitt, el carcinoma cloacogénico del recto y el sarcoma inmunoblástico, todas asociadas con virus DNA de la familia del Herpesvirus, además del carcinoma de células escamosas, asociado con el HSV, el linfoma de Burkitt con el EBV y el SK con el CMV (39-43). También, en Haití parecen ser endémicos tanto el CMV como el SK, lo cual parecería apoyar la teoría según la cual, una nueva cepa de CMV; o aún las conocidas, estarían causando el SIDA. Otras teorías, basadas también en el supuesto de un agente infeccioso postulan que un virus, posiblemente lento, como cualesquiera de los tres virus lentos de aparición reciente en Africa, podría haberse extendido hacia Haití y los Estados Unidos, produciendo la enfermedad (33). Hasta el momento, el primero de los señalados como agente etiológico no ha obtenido ninguna comprobación $(44,45)$. Para complicar más el análisis, algunos autores han puesto en tela de juicio el carácter neoplásico del SK, diciendo que una proliferación endotelial multicéntrica, la cual es característica del SK, no puede ser considerada como una neoplasia (24); además, se piensa que el brote de SK no puede haber sido tan abrupto, y que pudo haber muchos errores de diagnóstico en los años precedentes, que explicarían el bajo número de casos registrados de SK (8). Desde el primer momento de la epidemia, se ha pensado que distintas prácticas homosexuales podrían jugar un papel en la fisiopatología del síndrome $(19,46)$, y por ello se pensó asociarlo con el uso de los nitritos de amilo, compuestos orgánicos utilizados como estimulantes sexuales y como relajantes de la musculatura lisa del recto y el esfínter anal interno 347), y de los que se ha comprobado un efecto inmunosupresivo temporal (48). El gran número de casos de SIDA registrados sin exposición a los nitritos y la aparición de otras teorías más atrayentes le han restado importancia a la hipótesis (7). El uso de estrógenos con el fin de feminizar los rasgos de los homosexuales también se ha invocado como causa del SK, pero esto ha sido refutado (49) afirmando que el uso que los homosexuales hacen de los estrógenos es escaso y que si los estrógenos produjeran SK, millones de mujeres lo presentarían. El semen ha merecido especial atención como agente inmunosupresor (35), tanto más cuanto que hay pruebas de sobreexposición al mismo por vías oral y rectal en los homosexuales; no obstante lo anterior, ninguna de estas prácticas parece explicar por sí sola la aparición de una depresión irreversible de la inmunidad celular.

Hay dos teorías bastante minuciosas que conviene revisar:

Shearer (35) propone que los leucocitos alogénicos podrían ser el factor que induce 
la aparición de la inmunodeficiencia haciéndola irreversible. Estos leucocitos podrían transferirse a través del semen del sujeto activo al pasivo durante el acto sexual anal, entrando al torrente sanguíneo por soluciones de continuidad del recto o el ano. El semen suele estar contaminado con un pequeño número de leucocitos, que pueden aumentar en el caso de coexistir alguna enfermedad venérea o enfermedad autoinmune anti-espermática. Una vez que los leucocitos alcancen la circulación del huésped, podrían causar una inmunosupresión severa, como se ha observado experimentalmente. Aún más, se han informado cambios en los isotipos de las inmunoglobulinas similares a los encontrados en los enfermos de SIDA, cuando se inyectan leucocitos alogénicos por vía parenteral en el ratón. Si la inmunidad del receptor estuviera parcialmente suprimida por un virus, una droga, el semen, o cualquier combinación de éstos, los leucocitos alogénicos no serían rechazados y lograrían activar una señal supresora. Tal supresión, en los ratones sólo necesita incompatibilidad en un solo antígeno de la región I-A del complejo de histocompatibilidad H-2 (35). Es claro que el mismo caso podría darse en el ser humano. El autor propone otro mecanismo alterno mediante el cual los leucocitos alogénicos transferidos a personas infectadas con CMV podrían originar ciclos de replicación viral que a su vez iniciarían ciclos repetitivos de supresión inmunológica, inducidos por la partícula viral misma.

Esta teoría propone que los mecanismos fisiopatológicos podrían ser distintos en los otros grupos en quienes se presenta SIDA.

La segunda teoría (50) postula que podría ser el virus de la leucemia de células $T$ humana (HTLV) el agente causal del SIDA; hasta el momento, la teoría se apoya en los siguientes hallazgos: una mayor incidencia de anticuerpos contra HTV en los pacientes con SIDA que en los controles; el aislamiento de los dos grandes subtipos de HTLV, I y II e incluso de un tercero, en unos pocos pacientes enfermos de SIDA, y en uno con síndrome de linfadenopatía, una entidad que parece preceder la aparición del SIDA.
Otros hechos apoyan la teoría según la cual el HTLV sería la causa. El primero es la prevalencia de este virus en el área del Caribe y en Africa Ecuatorial. El segundo, es el marcado tropismo que tiene el HTLV por las células $\mathrm{T}$, dentro de las cuales infecta predominantemente a los linfocitos $\mathrm{T}$ cooperadores. El tercer punto es la similitud del modo de transmisión del AIDS y el HTLV: ambos se transmiten por contacto íntimo.

Finalmente, hay precedentes que indican que un virus puede causar leucemia e inmunosupresión, tal como lo ha demostrado Essex (51) en el caso del virus de la leucemia felina.

En contra de la teoría, están el corto período de tiempo que transcurre antes de que se instale la inmunodeficiencia, menor de un año, ya que el HTLV puede necesitar varios años antes de desarrollar la leucemia de células $\mathrm{T}(52)$.

Otra objeción la constituye la aparente ausencia de SIDA en Japón, área donde la tasa de infección con HTLV es muy alta (53).

Con respecto al grupo de enfermos de SIDA hemofílicos, sabemos que han sufrido IGO principalmente. Desde el año 1979 en el que se registraron estos primeros casos, ha habido por lo menos 20 millones de transfundidos en los Estados Unidos y varios lotes de concentrado de factor VIII se han exportado a Francia y Alemania Occidental, lo cual implicaría que, de ser un agente infeccioso el único responsable de la aparición de SIDA, habría un número muy elevado de casos en otros grupos aún descontando el presunto tiempo de incubación de la enfermedad, que como ya hemos mencionado, se estima menor de 2 años. También se sabe que la medicación antihemofílica y, en especial, el concentrado de factor VIII es inmunodepresiva (16), y no existe ninguna diferencia significativa en las tasas de mortalidad entre hemofílicos en los últimos 10 años. Antes de 1979 , morían 5 a 10 hemofílicos por año en los EUA a consecuencia de infecciones oportunistas y neoplasias muy raras que hoy serían cousideradas como SIDA. Como vemos, no se ha podido sacar conclusión alguna, y tanto éstos como los casos en 
quienes se pudo comprobar que el donante estaba enfermo de SIDA, esperan explicación.

Para terminar, recientemente se registró una epidemia de lo que parece ser SIDA en otro primate (Macacca mulatta) en un zoológico de los EUA, y se piensa que éste puede ser un modelo útil para el estudio de la enfermedad. También se postula que podría haber transmisión entre especies de un agente etiológico (54). El análisis de las costumbres y conductas sexuales de estos primates no-humanos revela que el coito anal, o incluso el simple contacto íntimo entre el pene de un macho y el recto de otro de menor jerarquía, puede ser un factor importante en el desarrollo del síndrome en ellos. También se ha puesto en duda la similitud de este síndrome entre los primates no-humanos y el SIDA de los seres humanos.

\section{MANIFESTACIONES CLINICAS}

El CDC define el SIDA como la aparición de sarcoma de Kaposi (SK) en hombres menores de 60 años y/o la presencia de infecciones por gérmenes oportunistas (IGO) en sujetos previamente sanos, que no padezcan enfermedades crónicas debilitantes ni estén recibiendo tratamientos inmunodepresores (15). Los motivos de consulta más frecuentes son la aparición de lesiones cutáneas (50\% de los casos), lesiones de la cavidad oral, adenopatías, fiebre, pérdida de peso y dificultad respiratoria (55).

Formas de presentación. Las formas clínicas se presentan como SK e IGO. Más recientemente, algunos casos se han tratado de clasificar como formas subclínicas, prodrómicas, e incluso frustras de SIDA (17, $56)$. Se piensa que podría haber un período de incubación de 6 a 12 meses y un período prodrómico sintomático de 3 a 6 meses caracterizado por fiebre inexplicable, sudoración nocturna, escalofríos, diarrea, fatiga, disminución de la libido e impotencia, depresión, apatía y linfadenopatía generalizada. Luego de ésto, harían su aparición el SK, la NPC o cualquier otra IGO.

Sarcoma de Kaposi. Las lesiones dérmicas características del SK constituyen la forma de presentación en el $26 \%$ de los casos de SIDA vistos $(14,57,58)$. Estas lesiones pueden ser pápulas o nódulos de tamaño diverso, indoloras y no pruriginosas, de color violáceo, multifocales que muestran tendencia a coalescer y formar placas. Se localizan principalmente en la mitad superior del cuerpo, especialmente en cabeza y cara (57). Se acompañan de fiebre, pérdida de peso y adenopatías generalizadas que aparecen semanas antes que las lesiones dérmicas, semejando un período prodrómico (21). Es frecuente observar un marcado compromiso visceral en especial del hígado y del bazo (con hepato y esplenomegalia); los huesos, el tracto gastrointestinal, el pulmón y la pleura están también afectados $(20,57)$. Se puede ver junto con otros tumores malignos como linfomas. El cuadro anterior se diferencia notoriamente del SK clásico cuyas lesiones comprometen generalmente miembros inferiores, evolucionando lentamente y en forma mucho menos agresiva, con un menor grado de compromiso visceral y una baja mortalidad. El SK visto como parte del SIDA evoluciona rápidamente, y en pocos meses conduce a la muerte. El SK visto anteriormente tenía una incidencia baja, y era una enfermedad característica de hombres mayores de 60 años, de ascendencia judía o provenientes del Mediterráneo (16, 21, 58).

Neumonía por P. carinii. El grupo más grande de enfermos de SIDA es el que se presenta como NPC $(51 \%)$. Hasta la aparición del brote reciente de infección pulmonar por P. carinii, (59) la neumonitis intersticial o neumocistosis se presentaba generalmente en niños con inmunodeficiencias congénitas o en individuos que recibían tratamientos inmunosupresores para el cáncer o para trasplantes de órganos (60). Se trata, pues, de una entidad que se ve más frecuentemente en sujetos con una respuesta inmunológica alterada de tipo celular (61). El cuadro de neumonitis aparece después de un corto período de afección de las vías respiratorias altas, luego del cual el paciente presenta fiebre sostenida, malestar general progresivo y tos húmeda no productiva. Poco después, dolor torácico de intensidad variable y disnea progresiva que puede llegar a insuficiencia respiratoria, a menudo mortal. A la auscultación pulmonar se pueden oír 
estertores finos acompañados o no de roncus $(20,55)$. En las radiografías de tórax se observan infiltrados pulmonares de tipo interstical, y menos frecuentemente de patrón retículo-nodular. En la mayoría de los casos el diagnóstico es tardío (21) pues sólo se empieza a considerar después de haberse administrado en forma adecuada un régimen de antibioticoterapia sin obtener mejoría alguna. Debido a que las secreciones son escasas y a que no es posible aislar el parásito, es necesario recurrir a la biopsia pulmonar por vía transbronquial o a cielo abierto para confirmar el diagnóstico, admitiéndose éste cuando se observa el microorganismo, utilizando la coloración de plata-metenamina, o en presencia de un exudado inflamatorio e infiltrado con células mononucleares, o finalmente, cuando el cultivo del tejido pulmonar resecado es negativo para cualquier otro gérmen (62). Este cuadro clínico puede anteceder o aparecer simultáneamente con el SK (21). En cuanto al manejo de la NPC, aparte de los cuidados generales del paciente y de las medidas especiales utilizadas en pacientes inmunosuprimidos, la terapéutica con trimethoprim-sulfa logra, a veces, controlar la infección y resolver el cuadro clínico y radiológico (55).

Otras infecciones. En las infecciones por virus del Herpes simple tipo II (HSV), las lesiones iniciales son vesículas que duelen y se acompañan de prurito. Se localizan generalmente en la región perianal donde, en virtud de la humedad, la fricción y el rascado, se ulceran y se infectan secundariamente llegando a formar úlceras crónicas de difícil manejo. En otros casos, la manifestación principal es un severo cuadro diarréico ocasionado por proctitis o colitis hemorrágicas acompañadas de adenopatías regionales. El cuadro evoluciona finalmente con diseminación de infecciones bacterianas sobreagregadas y sepsis mortal (63).

El resto de los casos de SIDA se presentan como SK y NPC asociadas $(8 \%)$, o como otras infecciones oportunistas $(15 \%)$, dentro de las cuales las más importantes son la neumonía, la meningitis o la encefalitis por Aspergillus, Candida albicans, Cryptococcus neoformans -con una incidencia muy alta recientemente registrada en Zaire-, Citomegalovirus, asociado en casi la totalidad de los casos de SIDA en homosexuales y registrado como asociación frecuente con el SK endémico del Africa Central; Nocardia, Strongyloides, Toxoplasma gondii, Mycobacterias atípicas, M. tuberculosis y Zygomicosis son otros de los microorganismos encontrados en los casos de SIDA. Se observan también esofagitis severas por Candida, CMV o HSV; leucoencefalopatía multifocal progresiva; enterocolitis prolongadas por Cryptosporidia e infecciones muy extensas y prolongadas por Herpes (14).

Diagnóstico. Aparte de los datos clínicos y epidemiológicos que permiten sospechar el diagnóstico, es posible precisarlo más mediante la utilización de pruebas de laboratorio $(6,24)$. Antes de exponer los resultados de las pruebas es necesario advertir que muchas de ellas no son específicas del SIDA, y que su validez y utilidad debe ser evaluada con cuidado. El número total de leucocitos en sangre periférica tiende a estar cerca del límite inferior normal (5.000 células /m3) o puede estar significativamente disminuído con marcada linfopenia (generalmente menos de 500 células $/ \mathrm{mm} 3$ ) (6). El número absoluto y el porcentaje de linfocitos $\mathrm{B}$, así como las concentraciones séricas de $\operatorname{Ig} \mathrm{A}$ e $\operatorname{IgM}$ son normales. Los niveles de IgG sérica están elevados. Mediante pruebas de fijación de complemento es posible determinar títulos de anticuerpos elevados contra CMV, HSV y Adenovirus (59). Las determinaciones cuantitativas de los factores C1q, C3, C4, C5 y C9 del complemento, así como su funcionalidad valorada mediante la capacidad hemolítica total son normales (6). Los monocitos están disminuídos en número y aunque conservan su capacidad bactericida, la respuesta a estímulos quimiotácticos está francamente deprimida $(6,59)$. Los polimorfonucleares circulantes son normales en número y funcionalidad.

Los hallazgos más importantes del SIDA se concentran en el estudio de los linfocitos $T$ $(1,6,59)$ en los cuales: el número absoluto es bajo; la respuesta de hipersensibilidad retardada a diversas combinaciones de antígenos como PPD, Candidina y Tricofitina 
es muy baja o está ausente; la respuesta de transformación blástica de los linfocitos $\mathrm{T}$ a mitógenos (fitohemaglutinina, concanavalina, etc.) y a antígenos de candida y a estreptoquinasa-estreptodornasa está disminuída $(6,59)$; finalmente, los resultados de las subpoblaciones de linfocitos $T$ muestran: marcada disminución de los linfocitos $\mathrm{T}$ cooperadores (TH); aumento del porcentaje de los linfocitos $\mathrm{T}$ supresores, y por consiguiente, una inversión de la relación cooperadores/supresores $(6,59)$. Aunque la inversión de dicha relación no es específica del síndrome, constituye un hallazgo constante en los sujetos que presentan IGO (59). Existe también un aumento del porcentaje de células $T$ que responden al antíguo T10, hallazgo también documentado en infecciones por EBV y CMV (59). El análisis de las subpoblaciones no está recomendado en la práctica clínica, debido a su alto costo.

Como vemos la inmunidad humoral está conservada, existiendo una gran alteración de la inmunidad celular cuantitativa y funcionalmente demostrada, con un aumento de la actividad de los mecanismos represores de la respuesta inmune, y una disminución marcada de los de amplificación.

Tratamiento. Aparte del manejo de las infecciones causada por gérmenes oportunistas, es necesario tratar el SK y tratar de encontrar la manera de revertir la inmunodeficiencia misma.

En cuanto al tratamiento del SK se piensa que cuando las lesiones están bien circunscritas o son únicas, el tratamiento debe ser la excisión local amplia o la radioterapia local superficial. Cuando la enfermedad se ha localizado en piel el tratamiento delineado suele ser suficiente. Una vez generalizado, el SK solo responde a la quimioterapia con diversas combinaciones de doxorrubicina, bleomicina, vinblastina y dacarbazina $(57$, 58). La mitad de los casos de SK tratados hasta la fecha fallecieron antes de los primeros 20 meses (16). Es fácilmente comprensible el por qué se ha logrado poco o casi nada en el tratamiento del SIDA, cuando no sabemos con certeza qué lo produce, y cuando los patrones de alteración de los mecanismos inmunitarios son tan nuevos y al parecer irreversibles. Por lo pronto, y aunque se han intentado varios tratamientos experimentales, todos con resultados muy pobres, el defecto parece ser irreparable y no hay nada que hasta ahora se haya podido hacer por detener la epidemia. Los cambios de conducta de la población homosexual de New York y San Francisco han logrado mantener el número de nuevos casos sin aumentar en los últimos meses. El CDC (64) y la Fundación Nacional para la Hemofilia en los EUA han redactado normas para proteger al personal de los laboratorios y clínicas, a los hemofílicos y otros posibles contactos; aunque se considera el SIDA como una enfermedad difícil de adquirir, como medidas preventivas se recomienda evitar el contacto con la sangre y el semen de los enfermos, a los cuales se les aconseja usar preservativos en las relaciones sexuales, evitar el intercambio de sangre o semen, limitar el consumo de estimulantes del tipo del nitrito de amilo y reducir el número de compañeros sexuales.

En Colombia no hay informe fundamentado de casos de SIDA. La vigilancia epidemiológica de grupos de alto riesgo nos parece una medida conveniente que es oportuno promover.

\section{BIBLIOGRAFIA}

1. CDC. Kaposi's sarcoma and Pneumocystis pneumonia among homosexual men - New York City and California. MMWR. 1981; 30, 305.

2. CDC Pneumocystis Pneumonia - Los Angeles. MMWR. 1981; 30, 250.

3. Marx, J.L. New disease baffles medical community. Science. $1982 ; 217,618$.

4. CDC. Follow-up on Kaposi's sarcoma and Pneumocystis pneumonia. MMWR. 1981; 30, 409.

5. CDC. A cluster of Kaposi's sarcoma and Pneumocystis carinii Pneumonia among homosexual male residents of Los Angeles and Orange Counties, California MMWR. 1982; 31, 305.

6. Gerstoft, J. y cols. Severe Acquired Immunodeficiency in European homosexual men. Br. Med. J. $1982 ; 285,17$. 
7. Gorin, I. y cols. Kaposi's sarcoma without the U.S. or "popper" connection. Lancet. 1982; ii, 908.

8. Maurice, P.D.L. y cols. Kaposi's sarcoma with benign course in a homosexual. Lancet. 1982; $i, 572$.

9. Thomsen, H.K. y cols. Kaposi's sarcoma among homosexual men in Europe. Lancet. 1981; ii, 688.

10. Du Bois, R.M. y cols. Primary Pneumocystis carinii and Citomegalovirus infections. Lancet. $1981 ; i i, 1339$.

11. CDC. Pneumocystis carinii pneumonia among persons with Hemophilia A. MMWR. 1982; 31, 365.

12. Groopman, J.E. y cols. Kaposi's sarcoma: and oncologic looking glass. Nature. 1982; 299, 103.

13. CDC. Unexplained Immunodeficiency and opportunistic infections in infants - New York, New Jersey, California. MMWR. 1982; 31, 665.

14. OPS. Síndrome de Inmunodeficiencia adquirida (SIDA). Boletín Epidemiológico. 1983; 4, 5.

15. CDC. Update: Acquired immune deficiency syndromme (AIDS) United States. MMWR. 1983; 32: 389

16. Marantz, R. AIDS: a new disease's deadly odyssey. The New York Times Magazine. 1983; Feb. 6, 26.

17. Detels, R. y cols. Relation between sexual practices and T-cell subsets in homosexually active men. Lancet. 1983; $i, 609$.

18. Moss, A.R. y cols. AIDS in the "gay" areas of San Francisco. Lancet. 1983; $i, 924$.

19. Editorial. Immunocompromised homosexuals. Lancet. 1981; ii, 1325.

20. Brennan, R.O. y cols. Gay compromise Syndrome. Lancet. 1981; ii, 1338.

21. CDC. Epidemiological aspects of the current outbreak of Kaposi's sarcoma and opportunistic infections. N. Engl. J. Med. 1982; 306, 248.

22. Giraldo, G. y cols. Int. J. Cancer. 1978; 22, 126. Citado en (16).

23. Wallace, J.I. y cols T-cell ratios in New York City prostitutes. Lancet. 1983; $i, 58$.

24. Wallace, J.I. y cols. T-Cell ratios in homosexuals. Lancet. 1982; ii, 908.
25. Dournon, E. y cols. AIDS in a Haitian couple in Paris. Lancet. 1983; $i, 1040$.

26. Autran, B. y cols. AIDS in a Haitian woman with cardiac Kaposi's sarcoma and Whipple's disease. Lancet. 1983; $i, 767$.

27. CDC. Opportunistic infections and Kaposi's sarcoma among Haitians in the United States. MMWR. 1982; 31, 353.

28. CDC Update on Acquired Immunodeficiency Syndrome (AIDS) among patients with Hemophilia A. MMWR. 1982; 31, 653

29. CDC. Possible transfusion-associated Acquired immunodeficiency syndrome (AIDS) - California MMWR. 1982; 31, 644 .

30. Brunet, J.B. y cols. AIDS in France. Lancet. $1983 ; i, 700$.

31. Clumeck, N. y cols. AIDS in black Africans. Lancet. $1983 ; i, 642$.

32. Vandepitte, J. y cols. AIDS and Cryptococcosis (Zaire, 1977). Lancet, 1983; $i, 925$.

33. Bygbjerg, I.C. AIDS in a Danish surgeon (Zaire 1976). Lancet. 1983; $i, 925$.

34. Marx, J.L. Health officials seek ways to halt AIDS. Science, 1983; 219, 271.

35. Shearer, G.M. Allogeneic leukocytes as a possible factor in inductions of AIDS in homosexual men. N. Eng. J. Med. 1983; 308, 223.

36. Kornfeld, H. y cols. T-lymphocyte subpopulations in homosexual men. N. Eng. J. Med. 1982; 307, 729.

37. Hersh, E.M. y cols. Elevated serum Thymosin 1 levels associated with evidence of immunedysregulation in male homosexuals with a history of infectious diseases or Kaposi's sarcoma. N. Eng. J. Med. 1938; 308, 45.

38. Drew, W. L. y cols. Cytomegalovirus and Kaposi's sarcoma in young homosexual men. Lancet. 1982; $i, 125$.

39. Conant, M.A. y cols. Squamous cell carcinoma in sexual partner of Kapposi's sarcoma patient. Lancet; $1982 ; i, 286$.

40. Doll, D.C. y cols. Burkitt's lymphoma in a homosexual. Lancet. 1982; $i, 1026$.

41. Spiers, A.S.D. y cols. Cytomegalovirus infection simulating Lymphoma in a homosexual man. lancet. $1982 ; i, 1248$. 
42. Li, F.P. y cols. Anorectal squamous carcinoma in two homosexual men. Lancet. 1982; $i, 391$.

43. Ziegler,J.L. y cols. Outbreak of Burkitt's-like Lymphoma in homosexual men. Lancet, 1982; i, 631.

44. Teas, J. Could AIDS agent be a new variant of African Swine Fever Virus. Lancet. 1983; i, 923.

45. Colaert, J. y cols. African Swine Fever Virus Antibody. not found in AIDS patients. Lancet. $1983 ; i, 1098$.

46. Editorial. Acquired Immunodeficiency Syndrome. Lancet. 1983; $i, 162$.

47. Anon. Amyl Nitrite and Kaposi's sarcoma in homosexual men. N. Eng. J. Med. 1982; 307, 893.

48. McManus, T.J. Amyl Nitrite use by homosexuals. Lancet. 1982; $i, 502$.

49. Mills, A.F. Kaposi's sarcoma and estrogens. Lancet. 1982; ii, 1965.

50. Marx, J.L. Human T-cell Leukemia virus linked to AIDS. Science. 1983; 220, 806.

51. Essex, M. y cols. Antibodies to Cell Membrane Antigens associated with Human T-cell leukemia virus in patients with AIDS Science. 1983; 220, 859.

52. Gallo, R.C. y cols. Isolation of Human T-cell leukemia virus in acquired immune deficiency syndrome (AIDS). Science 1983; 220, 865.

53. Barre'-Sinoussi, F. y cols. Isolation of a T-lymphotropic Retrovirus from a patient at risk for Acquired Immune Deficiency Syndrome (AIDS). Science. $1983 ; 220,868$.
54. Henrickson, R.V. Epidemic of Acquired Immunodeficiency in Rhesus monkeys. Lancet $1983 ; i, 388$.

55. Masur, H. y cols. An outbreal of communityacquired Pneumocystis carinii pneumonia. N. Eng. J. Med. 1981; 305, 1431.

56. Ragni, M.V. y cols. Acquired Immune deficiencylike syndrome in two haemophiliacs. Lancet. $1983 ; i, 213$.

57. Hymes, K.B. y cols. Kaposi's sarcoma in homosexual men a report of eight cases. Lancet. 1981; ii, 598 .

58. Rook, K.A. y cols. "Textbook of Dermatology" 1979; Ch. 66. Oxford.

59. Siegal, F.P. y cols. Severe Acquired Immunodeficiency in male homosexuals, manifested by Chronic perianal ulcerative Herpes simplex lesions. N. Eng. J. Med. 1981; 305, 1439.

60. CDC. Update on Kaposi's sarcoma and opportunistic infections in previously healthy persons United States. MMWR. 1982; 31, 294.

61. Costa, J. y cols. Generalised Kaposi's sarcoma is not a Neoplasm. Lancet. 1983; $i, 58$.

62. Gottlieb, M.S. y cols. Phenumocystis carinii Pneumonia and mucosal candidiasis in previously healthy homosexual men. N. Eng. J. Med. 1981; 305,1425 .

63. Vieira, J. y cols. Acquired Immunodeficiency in Haitians. Opportunistic infections in previously healthy Haitian immigrants. N. Eng. J. Med. $1983 ; 308,125$.

64. CDC. AIDS: precautions for clinal and laboratory staffs. MMWR. 1982; 31, 577. 